\title{
Nanohybrid materials from amine functionalization of sepiolite: Preparation, characterization and application as electrode modifiers for the electroanalytical detection of heavy metal ions
}

\author{
Ervice Ymélé, Jiokeng ZL Sherman, Tchieno MM Francis and Ignas Kenfack Tonle* \\ Chemistry of Materials and Electrochemistry, Department of Chemistry, Faculty of Science, University of Dschang, Cameroon
}

\begin{abstract}
Sepiolite-based organic-inorganic hybrid materials bearing amine groups were prepared by chemical grafting using 3-aminopropyltriethoxysilane (APTES) and [(3-(2-aminoethylamino)propyl)] trimethoxysilane (AEPTMS). The structural properties of the pristine sepiolite and the obtained composites materials were analysed using XRD, TG/DTA analysis and FTIR. The surface ion exchange ability of the functionalized clay minerals coated as thin film on glassy carbon electrodes and exposed to $\left[\mathrm{Ru}\left(\mathrm{NH}_{3}\right)_{6}\right]^{3+2+}$ or $\left[\mathrm{Fe}(\mathrm{CN})_{6}\right]^{3-/ 4-}$ electroactive probes was also investigated by multisweep cyclic voltammetry $(\mathrm{MSCV})$ and by Electrochemical impedance spectroscopy (EIS). From MSCV data, it was found that sepiolite and organosepiolites display a permselective behavior depending on the charge on its surface while EIS results showed that the functionalization of sepiolite enhanced its conductivity. The organosepiolites were tested in a comparative way for the voltammetric detection of mercury (II), and some preliminary experiments based on differential pulse voltammetry highlighted the interest of using the most sensitive organoclay (i.e. the sample grafted by AEPTMS) for the electroanalysis of several heavy metals in the same solution.
\end{abstract}

\section{Introduction}

The development of organic-inorganic composite materials combining at the nanometer scale the properties of their components has received much interest in the few past years. The resort to clays and clay minerals as inorganic parent support for such materials is due to their surface reactivity and ability to immobilize guest organic molecules, either within their structure or on their surface [1-3]. In fact, clay-based nanohybrid materials offer a wide range of applications in environmental protection [4-8], in catalysis [9-10], in polymer science [11-12] and in analytical electrochemistry [13-16]. In the last-mentioned application, composite materials derived from the modification of kaolinite [17-18] and smectite [19-23] as precursors are the most investigated, probably because these types of clay possess a layered structure favorable to intercalation processes and grafting reactions. At the opposite, the implication of fibrous clay minerals for electroanalytical purposes is scarce, although many works in literature have been devoted to their chemical modification [24-28]. Depending on the nature of the clay mineral, the preparation of organic-inorganic clay-based composite materials, exploited as electrode material proceeds mainly by two processes: (1) the intercalation of organic molecules within layered clay minerals such as kaolinite [29-32] and montmorillonite [1,33$36]$, and (2) the grafting of functionalized organic molecules onto the surface of clay minerals [6,37-40]. This last approach is convenient for all types of clay minerals bearing hydroxyl groups (aluminol or silanol) in their structure since it leads to the irreversible binding of the organic molecule on the clay surface. This aspect is of key importance when the desired organoclay bearing a specific functional group is to be exploited for the uptake from aqueous solution of a target species. This is the case in analytical electrochemistry where functionalized clay minerals are used as active component for the elaboration of organoclay-based composite electrodes. These modified electrodes have been shown to be useful in preconcentration electroanalysis and electrocatalysis, and for the elaboration of sensors or biosensors [41,42]. Two main types of electrodes are mostly exploited for electroanalytical purposes: (i) carbon paste electrodes incorporating a functionalized clay mineral and (ii) film-coated electrodes obtained by drop- coating or spin-coating a thin film of organoclay on the surface of a conventional solid electrode (e.g. glassy carbon, platinum or graphite) [42].

Sepiolite with the half-unit cell chemical formula $\mathrm{Mg}_{8} \mathrm{Si}_{12} \mathrm{O}_{30}(\mathrm{OH})_{4}\left(\mathrm{H}_{2} \mathrm{O}\right)_{4} \cdot 8 \mathrm{H}_{2} \mathrm{O}$ is a fibrous porous hydrated magnesium silicate $[26,43,44]$. Structurally, it is made up of blocks and channels extending in the fiber direction (c-axis). Each structural block is composed of two tetrahedral silicate sheets and central octahedral sheets containing $\mathrm{Mg}$. It possess silanol $(\mathrm{SiOH})$ groups located every $0.5 \mathrm{~nm}$ along the side of external channels while $\mathrm{Mg}(\mathrm{OH})_{2}$ form polar groups within the channels [26]. As for other types of clay minerals, it clearly appears that sepiolite can lend itself to grafting reactions, especially from silanol group it comprises. To the best of our knowledge, the use in electroanalysis of sepiolite modified by the grafting of functionalized

Correspondence to: Ignas Kenfack Tonle, Chemistry of Materials and Electrochemistry, Department of Chemistry, Faculty of Science, University of Dschang, P.O. Box 67 Dschang, Cameroon, Tel: +237 696141 545; Fax: +237 245 507 092; E-mail: ignas.tonle@univ-dschang.org

Key words: sepiolite, organoclay modified electrode, electroanalysis, differential pulse voltammetry, heavy metals

Received: November 29, 2017; Accepted: December 23, 2017; Published: December 26, 2017 
Ymélé E (2017) Nanohybrid materials from amine functionalization of sepiolite: Preparation, characterization and application as electrode modifiers for the electroanalytical detection of heavy metal ions

organosilanes is not yet reported. Therefore, the purpose of the present work was to explore the possibility of utilizing natural sepiolite as inorganic backbone for the preparation of composite materials, followed by their evaluation as electrode component for the detection of some toxic heavy metals in dilute solutions. Thus, the functionalization of sepiolite was achieved using 3-aminopropyltriethoxysilane (APTES) and [(3-(2-aminoethylamino) propyl)]trimethoxysilane (AEPTMS) selected as organosilanes bearing complexing amine groups known to display strong affinity for metal ions. The modified clays were characterized by X-ray powder diffraction (XRD, Fourier transform infrared (FTIR) spectroscopy, Thermogravimetric (TG) and Differential thermal analysis (DTA). The sample modified by AEPTMS displayed better sensitivity towards the electrochemical quantification of $\mathrm{Hg}^{2+}$ ions when coated on the surface of a glassy carbon electrode. It was further successfully employed as electrode modifier for the simultaneous detection of $\mathrm{Cd}^{2+}, \mathrm{Pb}^{2+}$ and $\mathrm{Hg}^{2+}$. The results obtained herein highlighted the application of organosepiolite as prominent composite material for the elaboration of amperometric sensors.

\section{Experimental}

\section{Clay mineral, chemicals and reagents}

Sepiolite (sample Sep-1) with the chemical composition (\%) of $\mathrm{SiO}_{2}: 52.9, \mathrm{MgO}: 23.6, \mathrm{Al}_{2} \mathrm{O}_{3}: 2.56, \mathrm{Fe}_{2} \mathrm{O}_{3}: 1.22, \mathrm{FeO}: 0.3, \mathrm{MnO}: 0.13$ and $\mathrm{K}_{2} \mathrm{O}: 0.05$ was obtained from the Source Clays Repository of the Clay Minerals Society (Purdue University, USA). It was purified according to already established procedures involving crushing, centrifuging and weak acid treatment to eliminate carbonates $[9,45]$. The claysized particles with equivalent spherical diameter $<2 \mu \mathrm{m}$ were used in further experiments.

All chemicals and reagents were analytical grade. The organic grafting agents were 3- aminopropyltriethoxylsilane (APTES) and [(3-(2-aminoethylamino)propyl)] trimethoxysilane (AEPTMS), obtained from Sigma-Aldrich; they were used without further purification. Toluene (99.8\%) was obtained from Merck. $\mathrm{NaOH}$ (> $98 \%$, pellets) was purchased from Fluka, $\mathrm{HNO}_{3}$ and $\mathrm{HCl}(>36 \%)$ from Riedel-de-Haën. For electrochemical measurements, dilutes $\mathrm{NaOH}$ and $\mathrm{HCl}$ solutions were used for $\mathrm{pH}$ adjustments. $\mathrm{K}_{3} \mathrm{Fe}(\mathrm{CN})_{6}(>99 \%$, Prolabo), $\mathrm{K}_{4} \mathrm{Fe}(\mathrm{CN})_{6}$ and $\mathrm{Ru}\left(\mathrm{NH}_{3}\right)_{6} \mathrm{Cl}_{3}$ (Alfa) were reagent grade and used as received. Analytical solutions containing heavy metals species were prepared by dissolving $\mathrm{Hg}\left(\mathrm{NO}_{3}\right)_{2}, \mathrm{~Pb}\left(\mathrm{NO}_{3}\right)_{2}$ and $\mathrm{Cd}\left(\mathrm{NO}_{3}\right)_{2}$ into redistilled water.

\section{Modification of sepiolite by graffing of orgnosilanes}

Organically modified sepiolites were prepared according to a procedure previously used in our group for the grafting of amino groups on smectite-type clay mineral [37]. Aminopropyl grafting sepiolite were obtained by refluxing a suspension made of $1 \mathrm{~g}$ of dried sepiolite in $20 \mathrm{~mL}$ of dry toluene to which $4 \mathrm{~mL}$ APTES were added dropwise for $2 \mathrm{~h}$ under constant stirring. After a slow cooling of the reaction mixture, the solid phase was recovered by filtration and washed three times with fresh isopropanol. The resulting products were then dried at $60^{\circ} \mathrm{C}$ overnight under vacuum. The resulting functionalized material is denoted Sep- APTES.

A similar procedure was used to functionalize the clay sample with AEPTMS: $1 \mathrm{~g}$ of sepiolite suspended in $20 \mathrm{~mL}$ toluene was refluxed and mechanically stirred for $1 \mathrm{~h}$ under dry nitrogen. To this suspension, 5 $\mathrm{mL}$ of AEPTMS were added dropwise. The mixture was refluxed for another $24 \mathrm{~h}$, filtered and washed with water, followed by methanol and isopropanol, and dried at $110^{\circ} \mathrm{C}$ overnight under vacuum. The modified sepiolite is hereafter referred as Sep- AEPTMS.

\section{Preparation of working electrodes}

Prior to their uses, Glassy carbon electrodes (GCE, $\varnothing=3 \mathrm{~mm}$ ) were polished with alumina slurries of different size $(1$, then $0.05 \mu \mathrm{m})$ on billiard cloth. Afterwards, they were placed in a 1:1 ethanol-water solution and properly cleaned in a sonicator for $10 \mathrm{~min}$ to eliminate any remaining alumina particles. Thin clay film working electrodes were prepared by "drop coating" $20 \mu \mathrm{L}$ of the aqueous dispersion ( $1 \mathrm{mg}$ of material in $1 \mathrm{~mL}$ water) of either pristine sepiolite or organonosepiolite on the active surface of the GCE, followed by 4 hours drying at room temperature before electrochemical experiments. The clay modified working electrodes are hereafter denoted GCE/Sep, GCE/Sep-APTES and GCE/Sep-AEPTMS, for a GCE modified by pure sepiolite, SepAPTES and Sep-AEPTMS respectively.

\section{Characterizations of materials}

The pristine clay mineral sample and its grafted counterparts were characterized by several physicochemical techniques.

Powder X-ray diffractometry (PXRD): Structural characterization by means of PXRD was performed on a Siemens D5005 diffractometer (Bruker AXS S.A.S) equipped with $\mathrm{Cu} K a$ radiation $(\lambda=0.15406 \mathrm{~nm})$ and operating at $45 \mathrm{kV}$ and $40 \mathrm{~mA}$.

Thermal analysis: Differential thermal analysis (DTA) and thermal gravimetric analysis (TGA) were performed on a SDT 2960 Simultaneous DSC-TGA instrument under $\mathrm{N}_{2}$ flow $\left(100 \mathrm{~mL} \mathrm{~min}{ }^{-1}\right)$ with a heating rate of $10^{\circ} \mathrm{C} \mathrm{min}^{-1}$.

Fourier transform infrared (FTIR): FTIR spectra were recorded using an Apha-P FTIR spectrometer supplied by Brucker. The samples were analysed at room temperature using $\mathrm{KBr}$ pellets (sepiolite and organosepiolites mass fraction $<10 \%$ ).

\section{Electrochemistry experiments}

Electrochemical experiments were carried out at room temperature with the $\mu$-Autolab potentiostat (Eco Chemie, Holland). A conventional three electrode cell configuration was employed. Film modified GCEs were used as working electrodes, with an $\mathrm{Ag} / \mathrm{AgCl} / \mathrm{KCl} 3 \mathrm{M}$ reference electrode (Metrohm) and a platinum wire as counter electrode. Multisweep Cyclic voltammetry (MSCV) was carried out in $0.5 \mathrm{M}$ $\mathrm{NaNO}_{3}$ (at $\mathrm{pH} 3$ ) containing $\left[\mathrm{Fe}(\mathrm{CN})_{6}\right]^{3-}$ or $\left[\mathrm{Ru}\left(\mathrm{NH}_{3}\right)_{6}\right]^{3+}$ redox probes to qualitatively characterize accumulation/rejection phenomena and mass transport issues through the various films. The accumulation (or repelling) process was appreciated by comparing the signals obtained at modified electrodes to those recorded using the bare GCE.

Electrochemical impedance spectroscopy (EIS) was used to characterize the electron transfer properties of the modified electrodes. The Nyquist plots were recorded with an OGS- 80 Origalys potentiostat (Origalys, France) coupled to a computer.

For the electrochemical sensing procedure, experiments were performed in two successive steps: an open-circuit preconcentration of the analyte on the working electrode surface, followed by voltammetric detection in a separate medium. For the first step, the working electrode was dipped in a beaker containing $10 \mathrm{~mL}$ of aqueous solution charged with the analyte at a given concentration, and kept under mild stirring. Upon preconcentration for a predetermined duration, the electrode was promptly removed and rapidly rinsed with distilled water, then 
Ymélé E (2017) Nanohybrid materials from amine functionalization of sepiolite: Preparation, characterization and application as electrode modifiers for the electroanalytical detection of heavy metal ions

transferred into the electrochemical cell containing the detection solution. The previously accumulated species were then analyzed by differential pulse voltammetry in anodic mode using the following parameters: pulse amplitude $50 \mathrm{mV}$, step potential $5 \mathrm{mV}$, equilibrium time $5 \mathrm{~s}$ and accumulation potential $-0.5 \mathrm{~V}$. Potential scan range was between $0.0 \mathrm{~V}$ and $+0.3 \mathrm{~V}$ for the electroanalysis of $\mathrm{Hg}(\mathrm{II})$ species, and from $-1.0 \mathrm{~V}$ to $+0.4 \mathrm{~V}$ for the simultaneous detection of $\mathrm{Cd}(\mathrm{II}), \mathrm{Pb}(\mathrm{II})$ and $\mathrm{Hg}(\mathrm{II})$ ions.

\section{Results and discussion}

\section{Characterization of materials}

DRX characterization: The XRD patterns of purified sepiolite and its functionalized derivatives are shown in Figure 1. The main diffraction peaks observed are listed in Table 1 that are associated with the clay mineral structure [46]. As main observation, no significant change did not occur on the diffraction peak position of sepiolite after the grafting of APTES and AEPTMS. In addition, the same diffraction peaks were found in pristine and grafted sepiolites, indicating that the structure of the clay mineral is maintained after modification.

This is evidenced by the fact that the functionalization of sepiolite occurs mainly by surface modification or by partial replacement of zeolitic water as previously demonstrated by several authors [26,27]. However, one can observed that most peak intensities decreased from natural sepiolite to its modified counterparts as a result of structural distortion occurring at the plane atoms in the sepiolite $[7,6]$.

Thermal analysis: Thermal analyses were performed on pristine and grafted sepiolites. The results expressed in terms of differential thermal analysis (DTA) plot, thermogravimetric curve (TG) and its first derivative (DTG) are shown in Figure 2. Four typical distinct weight losses were observed for raw sepiolite (Figure 2a): the first step occurring at $83^{\circ} \mathrm{C}$ is attributed to the loss of zeolitic water which takes place from $40^{\circ} \mathrm{C}$ and is completed at $200^{\circ} \mathrm{C}$. It is followed by two other steps in which sepiolite losses half of the coordinated water at $290^{\circ} \mathrm{C}$ while the remaining part of this water is removed around $520^{\circ} \mathrm{C}$. The last step occurs at $831^{\circ} \mathrm{C}$ and is relate to the departure of water related to structural $\mathrm{OH}$, that is to the endothermal dehydroxylation of sepiolite leading to the destruction of its structure $[26,43,44]$.

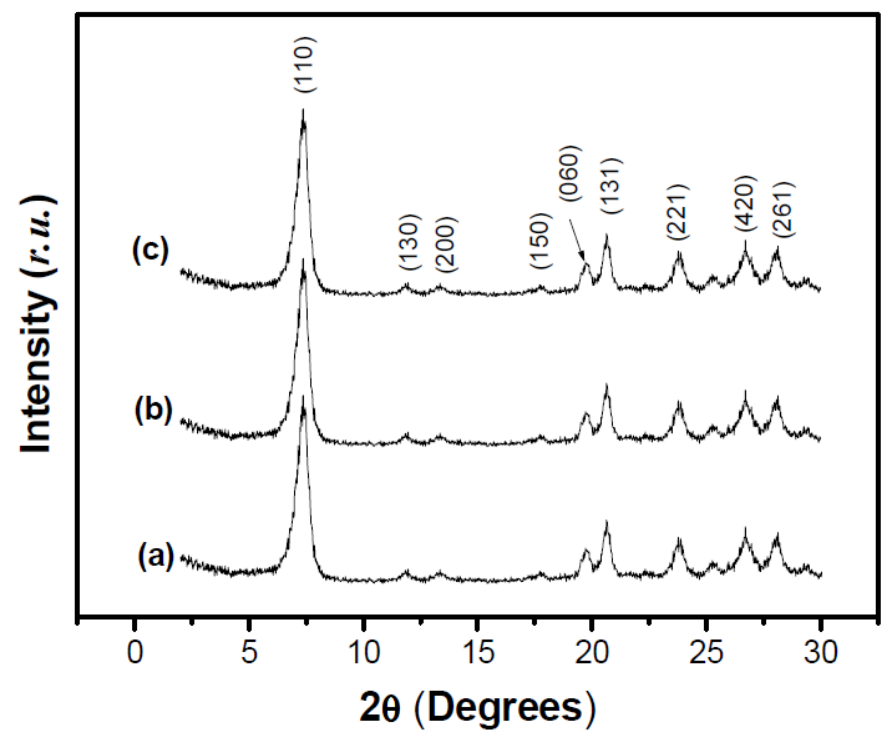

Figure 1. PXRD patterns of (a): Sep, (b): Sep-APTES and (c): Sep-AEPTMS.
Table 1. XRD indexes of pristine sepiolite and organo functionalized sepiolites.

\begin{tabular}{|c|c|c|c|c|}
\hline \multirow{2}{*}{$(\mathbf{h k l})$} & \multirow{2}{*}{$\mathbf{\theta}$} & \multicolumn{3}{|c|}{ Diffraction peak height } \\
\cline { 3 - 5 } & & Sep & Sep-APTES & Sep-AEPTMS \\
\hline$(110)$ & 7.32 & 576.92 & 434.48 & 426.67 \\
\hline$(130)$ & 11.82 & 48.15 & 33.79 & 46.67 \\
\hline$(200)$ & 13.64 & 46.15 & 35.17 & 40.00 \\
\hline$(150)$ & 18.18 & 38.46 & 47.58 & -- \\
\hline$(060)$ & 19.64 & 107.69 & 100.00 & 133.33 \\
\hline$(131)$ & 20.90 & 200.00 & 151.03 & 186.67 \\
\hline$(221)$ & 23.73 & 146.15 & 120.69 & 126.00 \\
\hline$(420)$ & 27.27 & 176.92 & 110.34 & 126.00 \\
\hline 261$)$ & 28.18 & 161.54 & 82.76 & 86.67 \\
\hline
\end{tabular}

The thermogravimetry and the first derivative curves of sepiolite modified with APTES are shown in Figure 2b. Six distinct weight losses are observed. The first weight loss $(2.40 \%)$ occurring at $48^{\circ} \mathrm{C}$ is attributed to the departure of zeolitic water. The second phenomenon centered at $182{ }^{\circ} \mathrm{C}(6.90 \%$ of total weight loss $)$ is attributed to the loss of APTES molecules from the channels of sepiolite. As in the case of the pristine sepilolite, the loss between 0 and $200^{\circ} \mathrm{C}(9.3 \%)$ is ascribed to zeolitic water. This may suggest that some water molecules in the channels of sepiolite are replaced by APTES molecules. The third weight loss observe at $300^{\circ} \mathrm{C}(2.85 \%)$ is due to the removal of water on dehydration while the fourth weight loss at $430^{\circ} \mathrm{C}(2.55 \%)$ is attributed to the degradation of APTES molecules attached to the silanol groups on the surface of sepiolite. The fifth weight loss at $520^{\circ} \mathrm{C}(2.40 \%$ of weight loss) similar to that occurring in pristine sepiolite is due to the removal of coordinated water, and the last one centered at $831^{\circ} \mathrm{C}(2.3 \%)$ is once more attributed to dehydroxylation of the sepiolite.

The thermogravimetric pattern of sepiolite modified with AEPTMS is shown in Figure 2c. Height distinct phenomena are clearly observed. Before $300^{\circ} \mathrm{C}$, three weight losses centered at $52^{\circ} \mathrm{C}, 91^{\circ} \mathrm{C}$ and $175^{\circ} \mathrm{C}$ are attributed to the removal physisorbed and zeolitic water, followed by the loss of hydratation water at $290^{\circ} \mathrm{C}$. The decomposition of AEPTMS molecules grafted on sepiolite surface occurs mainly between 300 and $700^{\circ} \mathrm{C}$, concomitantly with the removal of coordinated water. Finally, the destruction of the clay mineral structure is obtained at $831^{\circ} \mathrm{C}$.

FT-IR analysis of pristine sepiolite and organoclays: FT-IR experiments were performed to see if the organic molecules were successfully grafted on sepiolite. Figure 3(a) shows the infrared spectrum of pristine sepiolite, formed by two main absorption regions. The first zone between 3750 and $3000 \mathrm{~cm}^{-1}$ contains absorption bands at 3565 and $3393 \mathrm{~cm}^{-1}$ that correspond to the $\mathrm{OH}$ vibration of $\mathrm{Mg}-\mathrm{OH}$, or to the $\mathrm{OH}$ vibration of zeolitic water [34-35]. The second zone between 1700 and $500 \mathrm{~cm}^{-1}$ displays a first band at $1643 \mathrm{~cm}^{-1}$ attributed to the bending of zeolitic water. The peaks observed between 1200 and 400 $\mathrm{cm}^{-1}$ are characteristic of silicate backbone: the bands at 1204, 1050 and $806 \mathrm{~cm}^{-1}$ are assigned to $\mathrm{Si}-\mathrm{O}$ bond stretching vibration of Si-O-Si group [35]. The bands at 647 and $696 \mathrm{~cm}^{-1}$ correspond to Si-O stretching and $\mathrm{Mg}-\mathrm{OH}$ bond vibration respectively [36].

The spectra of sepiolite organically modified by APTES and AEPTMS are provided in Figure 3(b) and Figure 3(c), respectively. For both organoclays, the aliphatic $\mathrm{C}-\mathrm{H}$ stretching vibrations are found in the $3000-2700 \mathrm{~cm}^{-1}$ region. The peaks appearing at 2946, 2837 and $2872 \mathrm{~cm}^{-1}$ are attributed to asymmetric and symmetric $\mathrm{CH}$ vibrations of methoxy and ethoxy groups, and to the $\mathrm{CH}_{2}$ chains from the silane molecules [4]. The scissoring deformation mode due to $\mathrm{CH}_{2}$ groups are found at $1490 \mathrm{~cm}^{-1}$. All of these signals, absent on the spectrum of raw sepiolite confirm the modification of the clay mineral. One can additionally note that the band at $1643 \mathrm{~cm}^{-1}$ characteristic of zeolithic 
Ymélé E (2017) Nanohybrid materials from amine functionalization of sepiolite: Preparation, characterization and application as electrode modifiers for the electroanalytical detection of heavy metal ions
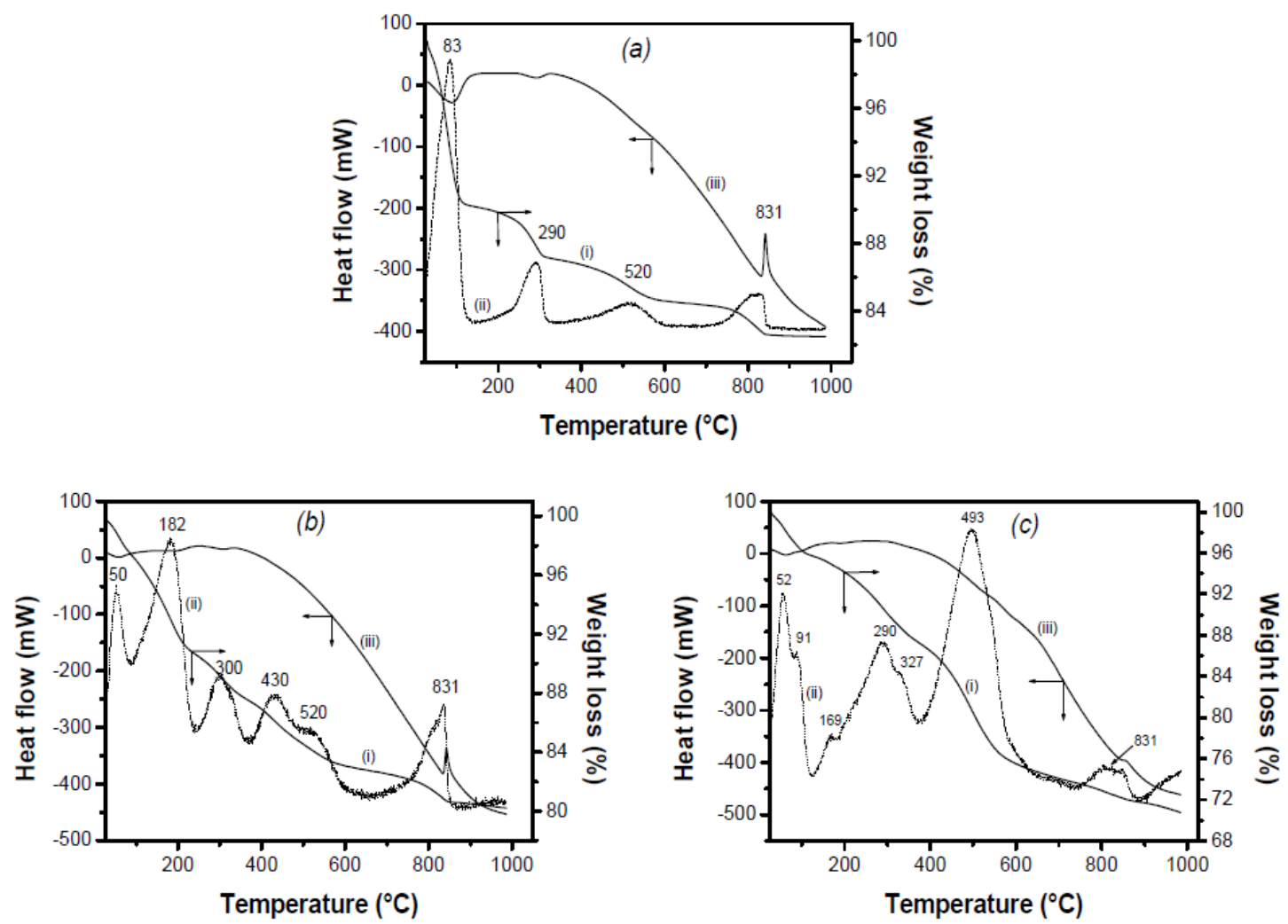

Figure 2. TG(i), DTG (ii) and DTA (iii) curves of (a): Sep, (b): Sep-APTES and (c): Sep- AEPTMS recorded under nitrogen atmosphere from room temperature to $1000^{\circ} \mathrm{C}$.

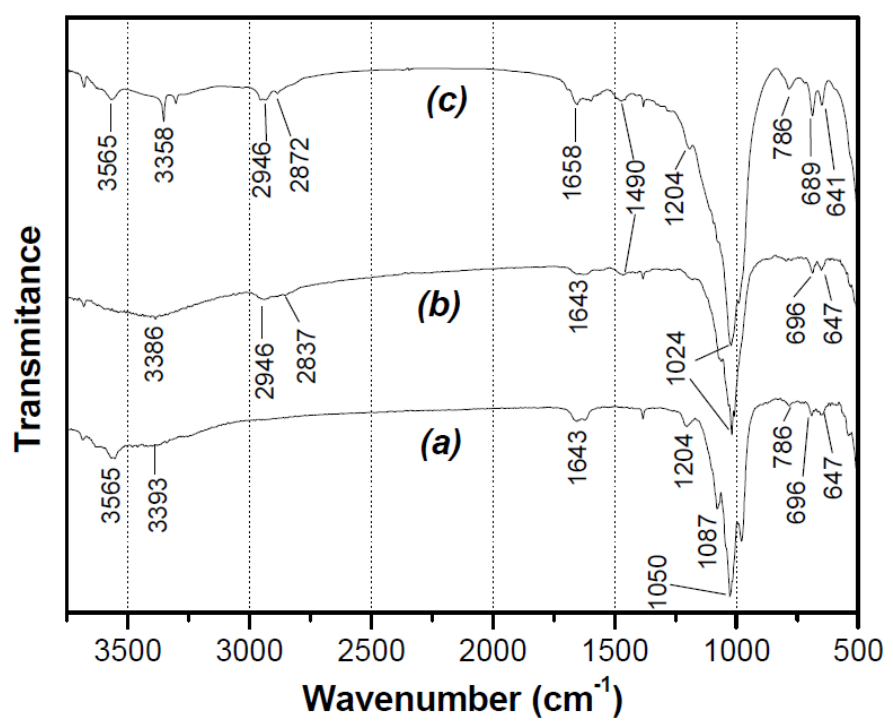

Figure 3. FTIR spectra of (a): Sep, (b): Sep-APTES and (c): Sep-AEPTMS materials.

water do not undergo change, suggesting that the oorganosilane molecules are not incorporated into the channels of sepiolite but have reacted with the external $\mathrm{Si}-\mathrm{OH}$ groups found on its surface [4] as expected.

Evaluation of grafted functional groups by Multisweep cyclic voltammetry: Sepiolite, a clay mineral with neutral fibers bears surface silanol groups available for coupling reactions. However, it is awaited that its modification by amino functionalization leads to changes in its surface electrical properties. In this respect, the charge on Sep-APTES and Sep- AEPTMS was investigated by multisweep cyclic voltammetry on the basis of permselectivity experiments. Thus, the ion exchange properties of these organoclays were tested using $\left[\mathrm{Fe}(\mathrm{CN})_{6}\right]^{3-}$ and $\left[\mathrm{Ru}\left(\mathrm{NH}_{3}\right)_{6}\right]^{3+}$ ions as standard redox probes. Figure 4(a) shows the cyclic voltammograms recorded in $0.5 \mathrm{M} \mathrm{NaCl}$ (with $\mathrm{pH}$ adjusted to 3$)+2 \times 10^{-4} \mathrm{M}\left[\mathrm{Fe}(\mathrm{CN})_{6}\right]^{3-}$ on a glassy carbon electrode modified with pure sepiolite. By cycling, a reversible system centered at $+0.25 \mathrm{~V}$ is obtained which results from the activity of $\left[\mathrm{Fe}(\mathrm{CN})_{6}\right]^{3-}$ ions physically adsorbed onto the surface of sepiolite. This surface was rapidly saturated as a stable voltammogram (with a peak current of 2.8 $\mu \mathrm{A}$ ) was obtained from the $2^{\text {nd }}$ to the $10^{\text {th }}$ cycle. By replacing the GCE/ Sep working electrode by GCE/Sep-APTES then GCE/Sep-AEPTMS, performing the same experiment as in Figure $4 \mathrm{a}$ leads to a different behavior as shown in Figure $4 \mathrm{~b}$ and Figure $4 \mathrm{c}$ : the continuous potential scan induces a gradual increase in peak currents with the number of scans, mostly in the cathodic direction. A steady state is reached upon 18 and 25 cycles, for GCE/Sep-APTES and GCE/Sep-AEPTMS respectively. The corresponding peak currents values were $6 \mu \mathrm{A}$ and $7 \mu \mathrm{A}$, that is about or more than 2 -fold higher the one recorded in Figure $4 \mathrm{a}$ with pristine sepiolite. This behavior could be attributed to the grafted amino groups on sepiolite that generate a partial positive charge at the electrode surface in acidic medium. The observed increase in peak currents is due to the accumulation of $\left[\mathrm{Fe}(\mathrm{CN})_{6}\right]^{3-}$ ions by the film of organoclays on the surface of the GCE, favored by electrostatic interactions between the positively charge amine groups and $\left[\mathrm{Fe}(\mathrm{CN})_{6}\right]^{3-}$ species bearing negative charge, as previously described in scientific literature by several authors $[19,47]$.

To confirm the idea that the uptake of $\left[\mathrm{Fe}(\mathrm{CN})_{6}\right]^{3-}$ is governed by electrostatic considerations, the experiments here above described were performed once more but by using the positively charged redox 
Ymélé E (2017) Nanohybrid materials from amine functionalization of sepiolite: Preparation, characterization and application as electrode modifiers for the electroanalytical detection of heavy metal ions
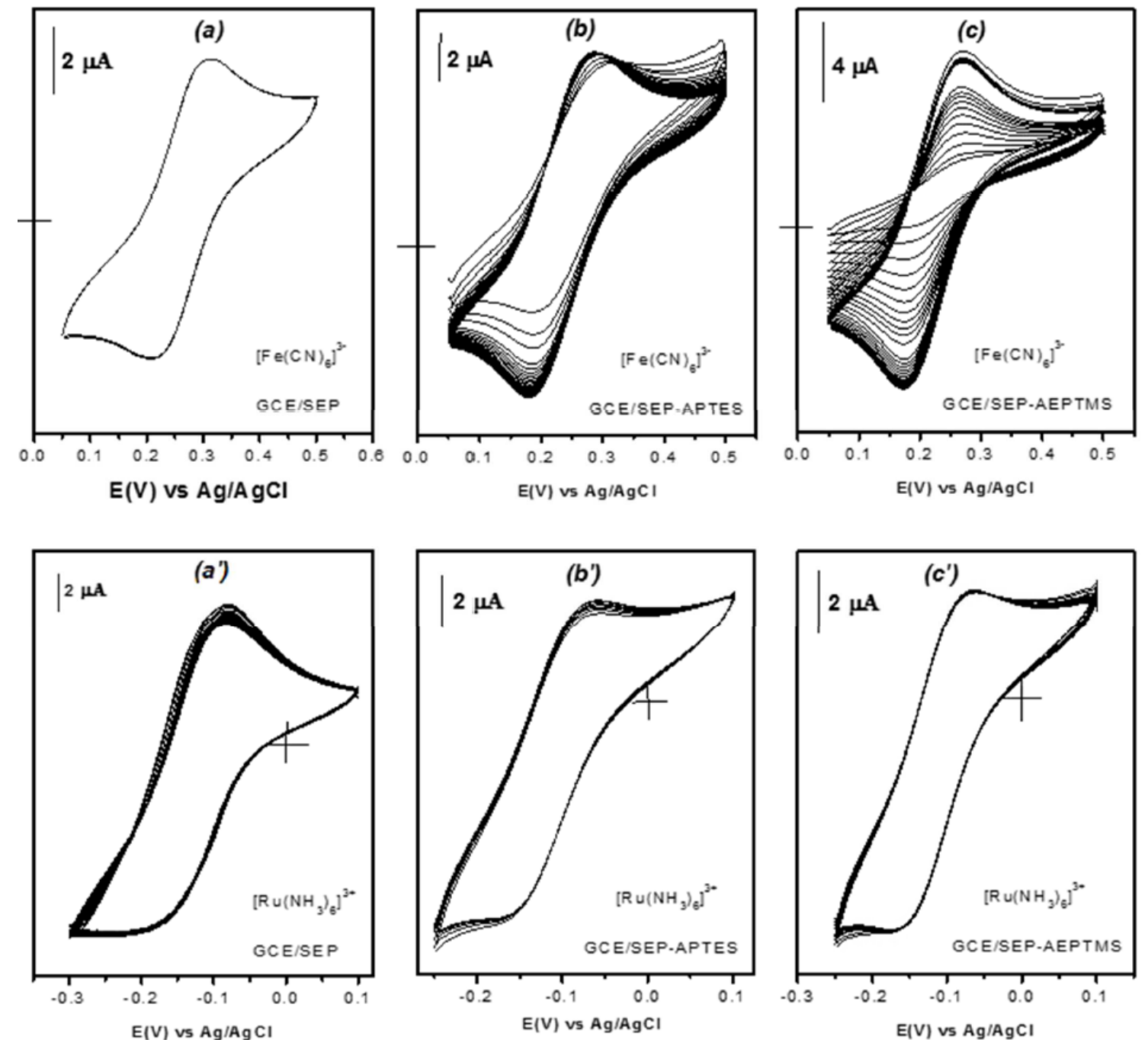

Figure 4. MSCV curves of $2 \times 10^{-4} \mathrm{M}\left[\mathrm{Fe}(\mathrm{CN})_{6}\right]^{3-}$ recorded in $0.5 \mathrm{M} \mathrm{NaCl}$ on the GCE modified with a film of (a) Sep; (b) Sep-APTES and (c) Sep-AEPTMS. Figures (a'), (b') and (c') correspond to the same working electrodes when in the supporting electrolyte $\left[\mathrm{Fe}(\mathrm{CN})_{6}\right]^{3-}$ species were replaced by $\left[\mathrm{Ru}\left(\mathrm{NH}_{3}\right)_{6}\right]^{2+}$ at a concentration of $10^{-3} \mathrm{M}$. The scan rate was $50 \mathrm{mVs}^{-1}$ for all voltammograms.

probe $\left[\mathrm{Ru}\left(\mathrm{NH}_{3}\right)_{6}\right]^{3+}$ : repetitive potential scans resulted in insignificant faradic response for all working electrodes as shown in Figure 4(a') to Figure 4(c'). Mainly, not increase in peak height was observed, the steady-state currents recorded on GCE/Sep-APTES and GCE/SepAEPTMS corresponding almost to that displayed by GCE/Sep. To conclude this section, one could admit that the efficiency of sepiolite before and after its functionalization is guided by electrostatic forces between the clay material on the electrode surface and that on the analyte. In addition, these results have confirmed the effectivity of the grafting of organosilanes on sepiolite surface as already shown by other characterization techniques.

Electrochemical Impedance Spectroscopy (EIS): EIS has been additionally used here to investigate the effect of sepiolite modification process observed in the previous section on the impedance of the GCE before and after the coverage of its surface by pure sepiolite and Sep-AEPTMS. Figure 5 presents the Nyquist plots of EIS experiments for unmodified GCE, GCE/Sep-AEPTMS and GCE/Sep. The main difference between the recorded curves is the evolution in the charge transfer resistance $\left(\mathrm{R}_{\mathrm{cc}}\right)$ values for $\left[\mathrm{Fe}(\mathrm{CN})_{6}\right]^{3-/ 4-}$ redox couple. On the bare GCE (Figure $5(\mathrm{a})$ ), the $\mathrm{R}_{\mathrm{ct}}$ value of $3470 \Omega$ was greater than that of GCE/Sep (Figure 5b), $1172 \Omega$ ) and GCE/Sep-AEPTMS (Figure 5c), $304 \Omega$ ).

These data clearly indicated that the grafting of AEPTMS on the surface of sepiolite favorably enhanced the rate of electron transfer, thereby facilitating the oxidation-reduction of the investigated redox probes. The performance of the aminosepiolite is associated to interactions between the $\left[\mathrm{Fe}(\mathrm{CN})_{6}\right]^{3-/ 4-}$ redox couple and the partial positive charge carried by amine groups of the organic modifier in mild acidic medium.

\section{Electroanalytical applications of organoclays for heavy metals sensing}

In order to highlight the possible use of grafted clay minerals as electrode modifiers for the electroanalysis of heavy metals species, some electrochemical experiments were performed that aim at compare the performance of both pristine and grafted sepiolites towards the detection of $\mathrm{Hg}(\mathrm{II})$ chosen as target pollutant model. In this respect, thin film modified electrodes were prepared to possess the same amount of clay material on the glassy carbon electrode. By applying the preconcentration-detection sequence as described in the 
Ymélé E (2017) Nanohybrid materials from amine functionalization of sepiolite: Preparation, characterization and application as electrode modifiers for the electroanalytical detection of heavy metal ions

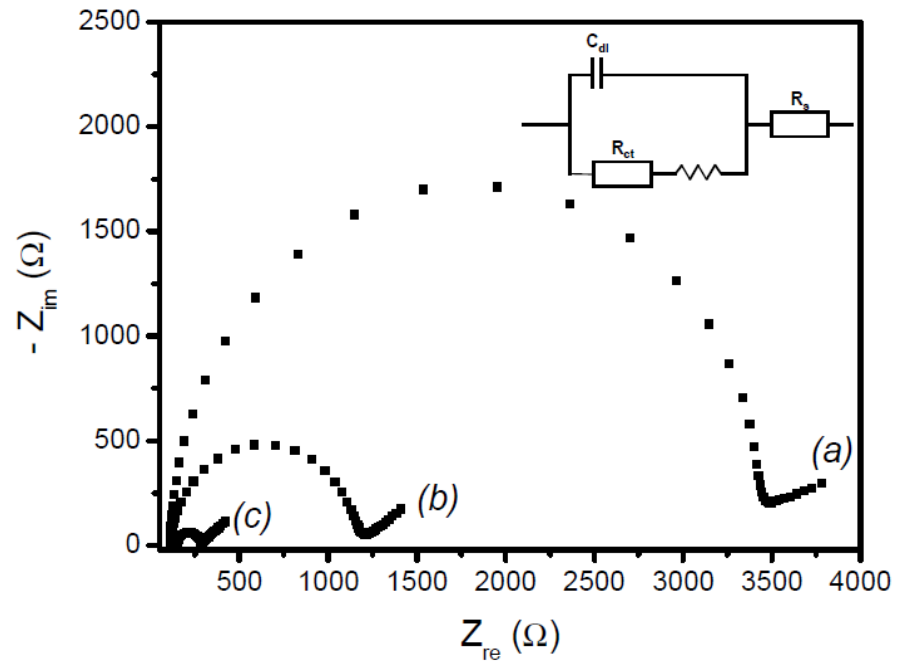

Figure 5. Nyquist plots showing the differences in the interface properties of sepiolite before and after grafting using AEPTMS. EIS was recorded in the presence of $5 \mathrm{mM}$ $\left[\mathrm{Fe}(\mathrm{CN})_{6}\right]^{3 / 4-}$ in $10 \mathrm{mM}$ Phosphate buffer solution $\left(\mathrm{pH} \mathrm{5)}+20 \mathrm{mM} \mathrm{K}_{2} \mathrm{SO}_{4}\right.$, using (a) the bare GCE, (b) GCE/Sep and (c) GCE/Sep-AEPTMS.

experimental section, the recordings obtained are displayed in Figure 6 that presents for the investigated modified electrodes the evolution of the anodic stripping voltammetry peak current of $10^{-5} \mathrm{M} \mathrm{Hg}$ (II) as detected in $0.05 \mathrm{M} \mathrm{HCl}$ after $10 \mathrm{~min}$ accumulation. One can clearly observed that the nature of clay material used as glassy carbon electrode (GCE) modifier has induced significant changes in the amperometric response of $\mathrm{Hg}(\mathrm{II})$. The ability to detect $\mathrm{Hg}(\mathrm{II})$ ions gave a capacity order of GCE/Sep < GCE/Sep-APTES < GCE/Sep-AEPTMS, with stripping currents of 3,7 and $14.5 \mu \mathrm{A}$, respectively. As compared to the GCE modified by pristine sepiolite (Figure 6(a)), the presence of grafted sepiolites gave better response in terms of peak current (Figure $6 \mathrm{~b}$ and Figure $6 \mathrm{c}$ ). Such a behavior could be reasonably attributed to the presence of amino functional groups on the electrode modifier, that are recognized to possess metal binding ability $[5,48]$. This explanation is further confirmed by the fact that GCE/Sep-AEPTMS is more sensitive than GCE/Sep-APTES, as a result of more $\mathrm{N}$ atomes binding sites on AEPTMS molecules compared to APTES. Yet, in the accumulation step, the uptake of $\mathrm{Hg}(\mathrm{II})$ is governed by the formation of $\mathrm{Hg}^{\mathrm{II}}-\mathrm{N}$ bonds.

In preconcentration electroanalysis devoted to the detection of a given heavy metal species, one main issue to be solved is the interference of others ions that are usually present in the medium under investigation. Concerning the detection of $\mathrm{Hg}(\mathrm{II})$ ions especially, $\mathrm{Pb}$ (II) and $\mathrm{Cd}(\mathrm{II})$ ions are known as common interfering species. Two situations are usually encountered when these ions are to be detected simultaneously: (1) the first one is the appearance of peaks related to these ions at close potentials, what renders difficult the identification of analytes, and (2) the mutual interaction between the investigated ions that causes an increase or decrease in peak currents of each other. Also in this section, the GCE/Sep-AEPTMS was dipped into a solution containing $\mathrm{Hg}(\mathrm{II}), \mathrm{Pb}$ (II) and $\mathrm{Cd}(\mathrm{II})$ ions all charged at a concentration of $10^{-5} \mathrm{M}$. Upon $10 \mathrm{~min}$ preconcentration, the DPV curves recorded in $0.05 \mathrm{M} \mathrm{HCl}$ are shown on Figure 7: it was noticed that the signal related to $\mathrm{Hg}(\mathrm{II})$ ions is not significantly influenced by the presence of $\mathrm{Pb}(\mathrm{II})$ and $\mathrm{Cd}(\mathrm{II})$, both in terms of peaks potential and current if one compares the response of $10^{-5} \mathrm{M} \mathrm{Hg}$ (II) shown in Figure 6(c). Yet, the electrochemical signal of $\mathrm{Pb}(\mathrm{II})$ and $\mathrm{Cd}(\mathrm{II})$ clearly appeared around $-0.5 \mathrm{~V}$ and $-0.7 \mathrm{~V}$, respectively. Apparently, the binding sites on the Sep-
AEPTMS at the GCE electrode seem not to be saturated due to the low concentration of the analytes in solution.

These preliminary results demonstrate the interest of using functionalized sepiolite instead of pristine clay mineral as sensing material for the simultaneous detection of $\mathrm{Hg}(\mathrm{II}), \mathrm{Pb}(\mathrm{II})$ and $\mathrm{Cd}(\mathrm{II})$ in the same solution. In a future work, our investigations will be focused on the optimization of the sensor herein proposed, in such a manner to use it in real natural media for the detection of heavy metals.

\section{Conclusion}

Two organosilanes bearing amine groups, namely 3-aminopropyltriethoxysilane and [(3-(2 aminoethylamino)propyl)] trimethoxysilane were grafted of the surface hydroxyl groups of sepiolite. The pristine clay mineral and the obtained organoclays were well characterized, and it was shown by XRD data that the fibrous structure of the clay is maintained upon functionalization, while the presence of the organic molecules were confirmed by FTIR and thermal analyses. New patterns of reactivity were induced on sepiolite due to the amino groups, as its binding capacity towards the uptake of metal ions

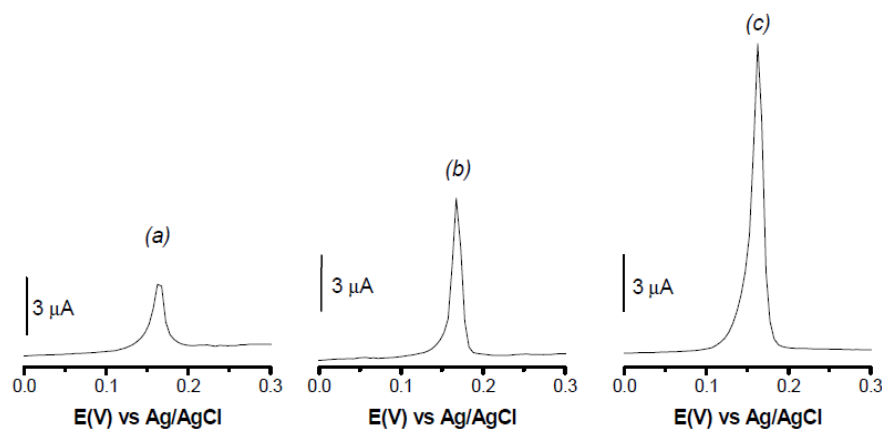

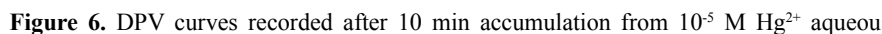
solution at $\mathrm{pH} 3$ on a GCE modified with a film of (a): Sep, (b): Sep-APTES and (c): SepAEPTMS. Detection was performed in $0.05 \mathrm{M} \mathrm{HCl}$ after $30 \mathrm{~s}$ electrolysis at $-0.5 \mathrm{~V}$.

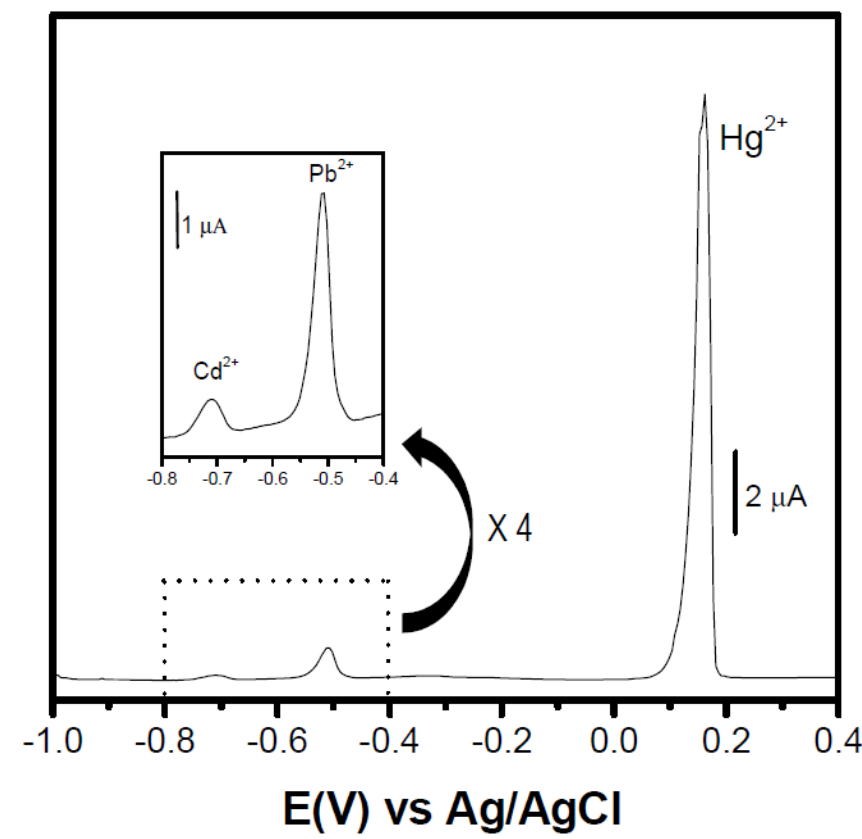

Figure 7. DPV curves recorded after 10 min accumulation in aqueous solution (at $\mathrm{pH} 3$ containing $10^{-5} \mathrm{M}\left(\mathrm{Hg}^{2+}, \mathrm{Cd}^{2+}\right.$ and $\left.\mathrm{Pb}^{2+}\right)$, on GCE/Sep-AEPTMS. Detection was performed in $0.05 \mathrm{M} \mathrm{HCl}$ after $30 \mathrm{~s}$ electrolysis at $-0.5 \mathrm{~V}$. 
Ymélé E (2017) Nanohybrid materials from amine functionalization of sepiolite: Preparation, characterization and application as electrode modifiers for the electroanalytical detection of heavy metal ions

significantly increased when the organoclays were applied as sensing materials in preconcentration electroanalysis. The results showed that the sepiolite sample functionalized using [(3-(2-aminoethylamino) propyl)] trimethoxysilane was more sensitive for the electrochemical detection of $\mathrm{Hg}(\mathrm{II}), \mathrm{Pb}(\mathrm{II})$ and $\mathrm{Cd}(\mathrm{II})$ species, and that it could be exploited as a potent electrode material for the simultaneous quantification of several heavy metals in aqueous media.

\section{Acknowledgements}

This work was supported by The World Academy of Sciences (TWAS) for the advancement of science in developing countries (Research Grant N¹6-515 RG/CHE/AF/AC_G-FR3240293302 allowed to I. K. Tonle).

\section{References}

1. Bergaya F, Lagaly G (2002) Surface modification of clay minerals. Appl Clay Sci 19: $1-3$.

2. Yilmaz N, Yapar S (2004) Adsorption properties of tretradecyl and hexadecyltrimethylammonium bentonites. Appl Clay Sci 27: 223-228.

3. Lemic J, Tomasevi-Canovic M, Djuricic M, Stanic T (2005) Surface modification of sepiolite with quaternary amines. J Coll Interf Sci 292: 11-19. [Crossref]

4. Turhan Y, Turan P, Dogan M, Alkan M, Namli H, et al. (2008) Charactezation and Adsorption Properties of Chemically Modified Sepiolite. Ind Eng Chim Res 47: 18831895.

5. Liang X, Xu Y, Tan X, Wang L, Sun Y, et al. (2013) Heavy adsorbents mercapto and amino functionalized palygorskite: Preparation and characterization. Colloid surf A Physicochem Eng Asp 426: 98-105.

6. Liang X, Xu Y, Sun G, Wang L, Sun Y, et al. (2011) Preparation and characterization of mercapto functionalized sepiolite and their application for sorption of lead and cadmium. Chem Eng J 174: 436-444.

7. Dogan M, Turhan Y, Alkan M, Namli H, Turan P, et al. (2008) Functionalized sepiolite for heavy metal ions adsorption. Desalination 230: 248-268.

8. Jal PK, Patel S, Mishara BK (2004) Chemical modification of silia suface by immobilization of functional groups for extractive concentration of metal ions. Talanta 62: 1005-1028. [Crossref]

9. Letaief S, Grant S, Detellier C (2011) Phenol acetylation under mild conditions catalyzed by gold nanoparticles supported on functional pre-acidified sepiolite. Appl Clay Sci 51: 236-243.

10. Ci LL, Pinnavaia TJ (1991) Organoclay assemblies for triphase catalysis. Chem Mater

11. $3: 213-215$.

12. Garcia-Lopez D, Fernandez JF, Merino JC, Santaren J, Pastor JM (2010) Effect of organic modification of sepiolite for PA 6 polymer/organoclay nanocomposites. Compos Sci Technol 70: 1429-1436.

13. Duan J, Shao S, Jiang L, Li Y, Jing P, et al. (2011) Nano-attapulgite functionalization by silane modification for preparation of covalent-intergrated Epoxy/TMPTMA nanacomposites. Iran Polym J 20: 855-872.

14. Jiokeng ZSL, Dongmo ML, Ymélé E, Ngameni E, Tonle IK (2017) Sensitive stripping voltammetry detection of $\mathrm{Pb}(\mathrm{II})$ at a glassy carbon electrode modified with an aminofunctionalized attapulgite. Sens Actuators B Chem 242: 1027-1034.

15. Ngassa PGB, Tonle IK, Ngameni E (2016) Square wave voltammetric detection by direct electroreduction of Paranitrophenol (PNP) using an organosmectite filmmodified glassy carbon electrode. Talanta 147: 547-555.

16. Ngassa PGB, Tonle IK, Walcarius A, Ngameni E (2016) Inorganic-organic hybrid material from the co-intercalation of a cationic surfactant and thiourea within montmorillonite layers. Application to the sensitive stripping voltammetric detection of $\mathrm{Pb}^{2+}$ and $\mathrm{Cu}^{2+}$ ions. CR Chimie 19: 789-797.

17. Ngassa PGB, Tonle IK, Walcarius A, Ngameni E (2014) One-step co-intercalation of cetyltrimethylammonium and thiourea in smectite and application of the organoclay to the sensitive electrochemical detection of Pb(II). Appl Clay Sci 99: 297-305.

18. Tonle IK, Letaief S, Ngameni E, Walcarius A, Detellier C (2011) Square wave voltammetric determination of $\mathrm{Pb}$ (II) ions using a carbon paste electrode modified by a thiol-functionalized kaolinite. Electroanalysis 23: 245-252.
19. Tonle IK, Letaief S, Ngameni E, Detellier C (2009) Nanohybrid materials from the grafting of imidazolium cations on the interlayer surfaces of kaolinite. Application as electrode modifier. J Mater Chem 19: 5996-6003.

20. Tcheumi HL, Tonle IK, Ngameni E, Walcarius A (2010) Electrochemical analysis of methylparathion pesticide by a gemini surfactant-intercalated clay-modified electrode. Talanta 81: 972-979. [Crossref]

21. Kemmegne JC, Tonle IK, Walcarius A, Ngameni E (2011) Electrochemical response of ascorbic acid and uric acid at organoclay film modified glassy carbon electrodes and sensing applications. Talanta 85: 754-762.

22. Bouwe RG, Tonle IK, Letaief S, Ngameni E, Detellier C (2011) Structural characterization of 1,10-orthophenanthroline-Montmorillonite intercalation compounds and application as low-cost electrochemical sensors for $\mathrm{Pb}$ (II) detection at the sub-nanomolar level. Appl Clay Sci 52: 258-265.

23. Kamga WK, Forano C, Hoggan PB, Tonle IK, Ngameni E, et al. (2013) Electrochemical determination of mesotrione at organoclay modified glassy carbon electrodes. Talanta 103: 337-343. [Crossref]

24. Volzone C, Rinaldi JO, Ortiga J (2006) Retention of gases by hexadecyltrimethyl ammonium- montmorillonite clays. J Environ Manag 79: 247-252.

25. Marjanovic V, Lazarevic S, Jankonjak I, Janackovic D, Petrovic R (2011) Chromium (VI) removal from aqueous solutions using mercaptosilane functionalized sepiolites. Chem Eng J 166: 198-206.

26. Tartaglione G, Tabuani D, Camino G (2008) Thermal and morphologica characterisation of organically modified sepiolite. Microp Mesop Mater 101: 161-168

27. Alkan M, Tekin G, Namli H (2005) FTIR and zeta potential measurement of sepiolite treated with some organosilanes. Microp Mesop Mater 84: 75-83.

28. Giora R, Assaf R, Yotam G (2011) Organo-sepiolite particles for efficient pretreatmen of organic wastewater: Application to winery effluents. Appl Clay Sci 51: 390-394.

29. Garcia N, Guzmain J, Benito E, Esteban-Cubillon A, Aguilar E, et al. (2011) Surface modification of sepiolite in aqueous gels by using methoxysilanes and their impact on the nanofiber dispersion ability. Langmuir 27: 3952-3959. [Crossref]

30. Komori Y, Sugahara Y, Kuroda K (1999) Direct intercalation of poly(vinylpyrrolidone) into kaolinite by a refined guest displacement method. Chem Mater 11: 3-6.

31. Matusik J, Klapyta Z, Olejniczak Z (2013) NMR and IR study of kaolinite intercalation compounds with benzylalkylammonium chlorides. Appl Clay Sci 83-84: 426-432.

32. Sato M (1999) Preparation of kaolinite amino acid intercalates derived from hydrated kaolinite. Clays Clay Miner 47: 793-802.

33. Zhang S, Liu Q, Cheng H, Zhang $\mathrm{Y}$, Li X, et al. (2015) Intercalation of $\gamma$ aminopropyltriethoxysilane (APTES) into kaolinite interlayer with methanol-grafted kaolinite as intermediate. Appl Clay Sci 114: 484-490.

34. Akçay M (2006) Characterization and adsorption properties of tetrabutylammomium montmorillonite (TBAM) clay: Thermodynamic and kinetic calculations. $J$ Colloid Interf Sci 296: 16-21. [Crossref]

35. Khaorapagong $N$ (2010) In situ complexation of thiourea in the interlayer space of copper(II)- montmorillonite. Appl Clay Sci 50: 414-417.

36. Lee SY, Echo WJ, Kim KJ, Ahn JH, Lee M (2005) Interaction between cationic surfactants and montmorillonites under nonequilibrium condition. J Colloid Interf Sci 284: 667-673. [Crossref]

37. Mojovic Z, Jovic-Jovici N, Milutinovic-Nikolic A, Bankovic P, Rabi-Stankovic AA, et al. (2011) Phenol determination on HDTMA-bentonite-based electrodes. J Hazard Mater 194: 178-184. [Crossref]

38. Tonle IK, Ngameni E, Njopwouo D, Carteret C, Walcarius A (2003) Functionalization of natural smectite-type clays by grafting with organosilanes: physico-chemical characterization and application to mercury(II) uptake. Phys Chem Chem Phys 5: 49514961.

39. Gardolinski JEFC, Lagaly G (2005) Grafted organic derivatives of kaolinite: I. Synthesis, chemical and rheological characterization. Clay Miner 40: 537-546.

40. Guimaraes AMF, Cimineli VST, Vasconcelos WL (2009) Smectite organofunctionalized with thiol groups for adsorption of heavy metal ions. Appl Clay Sci 42: 410-414.

41. Tejedor A, Nunes DG, Rubio J (2003) Adsorption of Cu ions onto a 1,10-phenanthroline grafted Brazilian bentonite. Clays Clay Miner 51: 58-64.

42. Mousty C (2004) Sensors and biosensors based on clay-modified electrodes-new trends. Appl Clay Sci 27:159-177 
Ymélé E (2017) Nanohybrid materials from amine functionalization of sepiolite: Preparation, characterization and application as electrode modifiers for the electroanalytical detection of heavy metal ions

43. Tonle IK, Ngameni E, Tchieno MMF, Walcarius A (2015) Organoclay-modified electrodes: preparation, characterization and recent electroanalytical applications. $J$ Solid State Electrochem 19: 1949-1973.

44. Avila LR, De-Faria EH, Ciuffi KJ, Nasser EJ, Calefi PS, et al. (2010) New synthesis strategies for effective functionalization of kaolinite and saponite with silylating agents. J Colloid and Interface Sci 341: 186-193. [Crossref]

45. Volle N, Giulieri F, Burr Q, Pagnotta S, Chaze AM (2012) Controlled interactions between silanol groups at the surface of sepiolite and an acrylate matrix: Consequences on the thermal and mechanical properties. Mater Chem Phys 134: 417-424.
46. Weir MR, Kuang W, Facey GA, Detellier C (2002) Solid-state nuclear magnetic resonance study of sepiolite and partially dehydrated sepiolite. Clays Clay Miner 50: 240-247.

47. Wan C, Chen B (2011) Synthesis and characterization of biomimetic hydroxyapatite/ sepiolite nanocomposites. Nanoscale 3: 693-700. [Crossref]

48. Tonle IK, Ngameni E, Walcarius A (2004) From clay to organoclay-film modified electrodes: tuning charge selectivity in ion exchange voltammetry. Electrochim Acta 49: $3435-3443$

49. Li J, Miao X, Hao Y, Zhao J, Sun X, Wang L (2008) Synthesis, amino-functionalization of mesoporous silica and its adsorption of Cr(IV). J Coll Interface Sci 318: 309-314.

Copyright: @2017 Ymélé E. This is an open-access article distributed under the terms of the Creative Commons Attribution License, which permits unrestricted use, distribution, and reproduction in any medium, provided the original author and source are credited. 